\title{
Análise Da Inserção Da Educação Ambiental Em Projetos Políticos Pedagógicos De Escolas Públicas De São Miguel Do Oeste - SC
}

\author{
Analysis Of Integration Of Environmental Education In Political Educational \\ Projects For Public Schools Of São Miguel Do Oeste - SC
}

\author{
Tiago Fernando Chaves ${ }^{1}$, Leila Cristina Aoyama Barbosa²
}

\begin{abstract}
${ }^{1}$ Bacharel em Ciências Biológicas UNOESC, Pós graduado em Ensino de Ciências - IFSC e Pós Graduado em Gestão Ambiental - UNINTER, São Miguel do Oeste - SC, Brasil

${ }^{2}$ Doutoranda do Programa de Pós Graduação em Educação Científica e Tecnológica - PPGECT, Universidade Federal de Santa Catarina
\end{abstract}

\section{Resumo}

Frente a crise ambiental e nocivos impactos ambientais, a Educação Ambiental destaca-se como ferramenta de conscientização socioambiental a longo prazo, devendo ser trabalhada de forma integradora, interdisciplinar, tema transversal nos currículos da educação formal. Essa pesquisa consiste em análise crítica de como a Educação Ambiental está inserida nos projetos escolares do ensino fundamental de três escolas públicas do município de São Miguel do Oeste- SC. Trata-se de uma pesquisa qualitativa e documental com posterior análise dos dados encontrados. Buscou-se levantar e conhecer as referências sobre transversalidade e a interdisciplinaridade do tema presentes nos projetos pedagógicos das instituições, ao mesmo tempo em que se empregou um questionário estruturado com questões fechadas, os quais foram respondidos por representantes com formação pedagógica. A análise dos resultados demonstra que a Educação Ambiental vem sendo desenvolvida principalmente por meio de projetos extracurriculares e não há base teórica ou modelos a serem trabalhados. A transversalidade e a interdisciplinaridade têm pouco ou insignificativas menções nos projetos, sem detalhamento necessário para sua prática efetiva. Os sujeitos entrevistados indicam que a temática vem sendo amplamente trabalhada e desenvolvida nessas escolas, de maneira tal que se torna necessário conhecer o desenvolvimento destes projetos escolares in loco.

Palavras-chave: Educação Ambiental; Projeto Político Pedagógico; Transversalidade; interdisciplinaridade; Sustentabilidade.

\begin{abstract}
Facing environmental crisis and harmful environmental impacts, Environmental Education stands out as the long-term environmental awareness tool and should be crafted cross integrative way, interdisciplinary subject in the curricula of formal education and as a central axis in Political Pedagogical Project. This research consists of critical analysis of how environmental education is included in school projects in primary education at three public schools in the municipality of São Miguel do Oeste -SC. It is a qualitative and desk research with subsequent analysis of the data found. Sought to rise and meet the references on cross-cutting and interdisciplinary theme in educational projects of the institutions, while that employed a structured questionnaire with closed questions, which were answered by representatives with teacher training. The analysis shows that environmental education has been developed primarily through extracurricular projects and there is no theoretical models or to be worked basis. The cross-cutting and interdisciplinary have little or insignificant mentions in projects without detail required for effective practice. The interviewees indicate that the theme has been extensively elaborated and developed in these schools, such that it becomes necessary to know the development of these school projects on the spot.
\end{abstract}

Keywords: Environmental Education; Project Political; transversality; interdisciplinarity. Sustainability. 


\section{Introdução}

A problemática ambiental tem assumido um relevante papel na sociedade, e vem se tornando um assunto de níveis "alarmantes", tendo impactos nocivos à qualidade de vida da população, isso sugere discussões, conscientização, mobilizações para atuar, de forma participativa e comprometida em defesa do ambiente natural e do meio social, da relação do homem com o meio ambiente.

Brugger (2004, p.12), ressalta que "a atual crise ambiental é, portanto, muito mais a crise de uma cultura, de um paradigma, do que uma crise de gerenciamento da natureza". Diante dessa problemática socioambiental, a Educação Ambiental (EA) vem a confrontar a ideia de Giddens (2009), segundo o "Paradoxo de Giddens", que ações ambientalmente corretas seriam práticas tardias para reverter o processo da degradação ambiental desenfreada pelo capitalismo, uma vez que seria uma ação preventiva ao conscientizar as gerações futuras se teria um resultado efetivo a longo prazo, comprometendo as necessidades de uma conscientização ambiental imediata (ANDRADE; RIBEIRO, 2011).

Frente a esse cenário de consumo ambientalmente impactante, a EA passa a ser uma ferramenta necessária para o desenvolvimento de um modelo de reflexão, tendo assim um papel crucial para o exercício da cidadania, tendo como objetivo ser cada vez mais persuasiva e popularmente inserida nos diferentes segmentos da sociedade. No entanto há necessidade de se trabalhar nas escolas o meio ambiente como tema transversal, através da EA que dialogue com a realidade e com problemas quotidianamente vividos pelos alunos (KIST, 2010).

Os Parâmetros Curriculares Nacionais relatam que as séries finais, assim como as séries iniciais do Ensino Fundamental, trabalham com temas transversais, proporcionando a construção de uma educação integradora, e a uma didática voltada às necessidades de um trabalho elaborado de maneira interdisciplinar (BRASIL, 1998). Coimbra (2008), refere-se à necessidade de se pensar na EA de forma interligada ao método interdisciplinar, suas perspectivas pedagógicas devem se apresentar em todas as disciplinas. Nesse sentido a EA permite enfatizar as relações entre a humanidade, o desenvolvimento, o meio natural e as relações sociais, sem deixar de lado as especificidades de cada disciplina. Conforme Isaia (2001, p.4), "para a EA constituir-se como temática transversal deve estar em todo os conteúdos e não restringido apenas algumas matérias previamente estabelecidas nas estruturas curriculares que regem o ensino. "

Segundo conclusão de pesquisas relacionadas a EA nas escolas, as instituições de ensino podem desenvolver essa temática através de projetos socioambientais com a comunidade, disciplinas especiais, de forma multidisciplinar e transversal, formulando esse leque de possibilidade durante o desenvolvimento do Projeto Político Pedagógico (PPP) (TRAJBER e MENDONÇA, 2006).

Segundo Silva (2009, p.01) "o PPP é o documento que reflete o posicionamento da escola frente à sociedade. Assim sendo, não pode ser estático, sofre constantes mudanças na busca por melhorar a qualidade escolar". Já para Veiga (2003, p. 27) “os PPPs são documentos norteadores, roteiros programáticos, nos quais devem estar claras as principais ideias, seus fundamentos, uma orientação curricular para a organização das instituições educativas."

Diante de toda essa complexidade que a EA representa e o fator de impacto que causa no desenvolvimento sustentável, bem como na qualidade de vida e em prol da responsabilidade socioambiental faz-se necessário avaliar as práticas pedagógicas utilizadas na EA escolar e de que forma qualitativamente essas práticas são eficientes para a construção dos conhecimentos ambientalmente responsáveis e seus reflexos na sociedade.

Em nível nacional a lei no . 9.795, de 27 de abril de 1999, é referida a EA e institui a Política Nacional de Educação Ambiental, estabelecendo que a EA é essencial e deve abranger todos os níveis de ensino em caráter formal e não formal dando enfoque ao humanismo, holístico, visando a sustentabilidade.

Se analisar a proposta curricular de Santa Catarina (1998), ela se caracteriza por ser amplamente socioambiental. Segundo o documento que rege o plano pedagógico, a função da EA é ter um papel na formação de um cidadão consciente e crítico, sendo ele capacitado nas ações diretas na realidade socioambiental, tomando como base o comprometimento com a vida e a peculiaridade de cada região. Com 
isso essa proposta curricular tem a posição de atingir todas as áreas do currículo, devendo estar claros nos PPPs que orientam os planos curriculares.

Diante desse compromisso, as escolas catarinenses poderiam enfatizar, aplicar e reger a EA em seus PPPs, instituindo-o de forma participativa, democrática, reflexiva, permitindo a todos os cidadãos a construção de uma consciência socioambiental.

Pouco se tem relatado em bibliografias sobre a forma que EA vem sendo trabalhada e qual seu enfoque nos PPPs na região Oeste de Santa Catarina e qual o nível de preparo dos educadores nas abordagens didáticas interdisciplinares da EA. Tão pouco se sabe do interesse dos alunos e o quanto o assunto é absorvido e repassado em ações ambientalmente sustentáveis na sociedade catarinense.

Diante de todas as abordagens teóricas, fica evidenciado a importância de se revisar e se necessário reformular os projetos que orientam as práticas pedagógicas da EA, trabalhando-a de forma transversal e interdisciplinar, nessa linha de pesquisa, o referido trabalho tem em sua pretensão de verificar a EA nos PPPs das instituições públicas de ensino de São Miguel do Oeste-SC.

\section{Revisão Teórica}

Kruguer (2001) quando relata a interação do homem com a natureza nos primórdios da humanidade, coloca que entre 50 e 40 mil anos atrás essa natureza dominava o homem, entretanto após o surgimento da agricultura a cerca 10 mil anos o ser humano passou a reverter essa relação e hoje o homem moderno domina e a transforma e consequentemente sofre os reflexos da sua má utilização, a qual tem impacto direto no clima e na vida na terra.

Nesse sentido cabe destacar que a EA assume cada vez mais uma função transformadora, na qual a co-responsabilização dos indivíduos torna-se um objetivo essencial para promover um novo tipo de desenvolvimento sustentável. Essa conscientização está cada vez mais enfocada nas mídias atuantes, proporcionando assim que a EA esteja sendo difundida e incorporada por diversos segmentos da sociedade, entretanto ainda é necessário que ocorra uma análise aprofundada para uma mobilização efetiva por parte da sociedade (COSTA, 2013).

A EA é uma ação oriunda da Conferência Intergovernamental de Tbilisi (1977), definida por Dias [2003 p.98] como: "dimensão dada ao conteúdo e à prática da educação, orientada para a resolução dos problemas concretos do meio ambiente através de enfoques interdisciplinares e de uma participação ativa e responsável de cada indivíduo e da coletividade".

Já em nível nacional a lei no. 9.795, de 27 de abril de 1999, refere-se à EA e institui na Política Nacional de Educação Ambiental, estabelecendo que a EA é essencial é deve abranger todos os níveis de ensino em caráter formal e não formal dando enfoque holístico, visando a sustentabilidade.

Assim podemos afirmar que o objetivo primordial da EA é reinventar os indivíduos em seus conceitos de coletividade, mudando assim suas práticas de consumo e utilização dos recursos naturais existentes, ou seja, estabelecer processos educativos que favoreçam a realização de movimentos favoráveis à defesa e qualidade da vida. No que diz respeito às práticas educativas na EA nas escolas, Menezes (2012), traz as teorias onde coloca que é necessário um foco no objetivo pedagógico, sendo efetivo nas atividades que proporcionam certo grau de ensinamentos a nível que possam conduzir os alunos ao uso racional de recursos naturais e a manutenção nos processos produtivos que envolvam os ecossistemas naturais ou aqueles gerenciados pelo homem, construindo assim uma profunda mudança de valores socioambientais, caracterizando uma visão holística de mundo.

A contribuição dos temas transversais como o meio ambiente, torna-se um requisito básico na formação, construção e no desenvolvimento de uma consciência ambiental. Essa temática transversal, tem por sua finalidade a formação de cidadãos ambientalmente conscientes, aptos a decidir, atuar e fiscalizar as ações potencialmente degradadoras do meio ambiente e dos recursos naturais, de modo comprometido com a sociedade e com a qualidade ambiental (DIAS, 2003). 
A transversalidade cria e possibilita novas dimensões, favorecendo a inclusão de saberes extraescolares. Araújo e Santos (2009) ressaltam que uma perspectiva de ensino na formação do professor torna necessário, empenhando-se em um pensar transversal, aonde as perspectivas transversais apontem para uma reformulação das práticas pedagógicas, rompendo assim a alienação dos docentes em fixar-se nas atividades pedagogicamente padronizadas.

Para Santos, 2008, p.134 a transversalidade e a interdisciplinaridade fundamentam-se na crítica da visão de conhecimento que trata a realidade como um conjunto de dados estáveis, sujeitos a um ato de conhecer isento e distanciado. As duas consideram a complexidade do real e a importância de valorizar a teia de relações, que têm aspectos variados e contraditórios.

Pereira, Bittar e Grigoli (2005) referem-se a transversalidade e a interdisciplinaridade de uma forma crítica de se trabalhar a complexidade realista, ou seja, são questões as quais pode ser vivenciada e que influenciam as dinâmicas macrossociais, comportamentos culturais e conflitantes, que exigem um determinado ensino e aprendizagem relativos aos seus conteúdos.

Pesquisadores como Guimarães (2004) e Carvalho (2006) enfatizam as dificuldades das escolas em desenvolver novos trabalhos de forma transversal e interdisciplinar, segundo esses pesquisadores essa dificuldade é reflexo da desintegração das concepções pedagógicas empregadas pelos docentes, enraizadas em uma visão reducionista que na maioria dos casos está baseada na EA como disciplina específica.

Luck (2003) nos traz a ideia que a Interdisciplinaridade é um recurso que envolve a união e a participação dos docentes num processo em equipe, gerando interações entre disciplinas do currículo escolar com a realidade social, suprindo a fragmentação do ensino, sendo objetivo na formação integral de alunos socialmente ativos, com uma visão holística do mundo, com competência de confrontar os problemas complexos como os impactos e a degradação ambiental.

Interdisciplinaridade deve superar a fragmentação das disciplinas, proporcionando a construção de um conhecimento complexo, levando em conta ainda a importância individual de cada matéria.

No ensino fundamental há significativos obstáculos para se trabalhar com uma visão mais global e realista, uma vez que constantemente a construção do conhecimento é realizada de forma fragmentada pelas disciplinas que compõem a grade curricular. Assim cada docente deve trabalhar a temática ambiental dentro de sua disciplina de competência, cooperando para que cada aluno desenvolva sua visão holística sobre o meio ambiente (TOMAZELLI; FERREIRA, 2001.)

Além das tradicionais disciplinas que trabalham com conteúdos relacionados as temáticas ambientais como Ciências, Geografia e História, torna se fundamental que as demais matérias abordem de forma interdisciplinar a EA.

Assim MIRANDA et al 2010, p.14 exemplifica que a Língua Portuguesa poderá trabalhar com textos relacionados aos valores propostos pela Educação Ambiental; Arte através das diversificadas expressões teatro, música, sensibilizando para um ambiente de qualidade; Matemática propondo interpretações de dados estimulando a aquisição de novos hábitos de desenvolvimento sustentável como economia, racionalizando, reutilização e reciclagem dos recursos naturais; Educação Física ajudando na compreensão da relação do corpo com o ambiente.

Segundo Kist (2009), quando se trata do domínio do conhecimento na construção da EA, ocorrem que professores trabalham de uma forma mais Crítica/Emancipatória/Popular, quanto outros enfatizam em uma construção mais Tradicional/Convencional. Ainda segundo a autora a negligência de um aprofundamento mais crítico, histórico, política e social da problemática ambiental são fatores que influenciam nestas diferentes concepções.

Conclusões análogas entre vários autores referencie a transversalidade e a interdisciplinaridade como grandes obstáculos a serem driblados pelos educadores na hora de efetivamente praticá-las, a questão pertinente de é como trabalhar os diferentes conteúdos 
disciplinares, seguindo uma perspectiva da transversalidade e da interdisciplinaridade (LEITE; MEDINA, 2001).

Frente a esses obstáculos torna-se necessário nortear e orientar os trabalhos escolares. Cada escola tem como dever formular seu PPP, administrando-o no âmbito da sua realidade, sendo esse projeto considerado como um documento em constante construção, discussões e aperfeiçoamentos, com resultados a curto e longo prazo, tendo caráter inovador e articulador, permitindo ser um meio coletivo para integrar, dando a todos os cidadãos condições de acesso e permanência na escola, garantindo a qualidade de ensino a humanidade, criando e buscando alternativas para os diferentes estágios dos trabalhos pedagógicos (VEIGA, 1995).

Para Miranda et al (2010), a criação, implantação e o desenvolvimento dos PPPs obedecem às orientações da Lei de Diretrizes e Bases da Educação Nacional (LDB), Lei no 9.394, de 20 de dezembro de 1996, nos seus respectivos artigos 12, 13 e 14. Os autores ainda enfatizam que os PPPs têm características peculiares, por exemplo ser elaborado de forma de democrática, possibilitando a inclusão voltada a diversidade dos alunos, e ainda abrangendo os desafios das abordagens das deficiências educacionais, dos êxito e fracassos educacionais. Os PPPs quando elaborado, executado e avaliado, favorecem o processo educativo e o papel das instituições educativas com a formação intelectual dos alunos.

Os PPPs nos últimos anos têm ganhado espaço no âmbito das discussões sobre a EA brasileira, sua elaboração representa um desafio para toda a comunidade escolar, em que significativas pesquisas tornam-se crucias para constituir uma análise de como se trabalhar a formação desse documento envolvendo a EA, o qual poderiam ser tema central na programação dos PPPs, pois sua relevância das temáticas do PPPs e a EA são algo indissociáveis (SILVA, 2003).

É relevante o número de trabalhos e autores que mencionam e avaliam os empecilhos dos PPPs deficitários frente a orientações socioambientais das atividades de EA. Essas dificuldades vêm da falta de qualidade e participação nos processos de implantação do PPPs e da abrangência dos temas e dos seus objetivos.

Silva (2009), em sua pesquisa que investigou o posicionamento da EA nos PPPs das escolas estaduais de Manaus - AM, encontrou projetos semelhantes, enfocados nas matérias tradicionais e culturais, eles até apresentavam eixos interdisciplinares, entretanto careciam de uma visão teórica elaborada para orientar atividades e metas relativas à EA. Dentre as escolas pesquisadas nenhuma apresentou em seus projetos pedagógicos preocupação ambiental, mesmo que previsto na legislação atual, o autor ainda relata que o ambiente no qual estão localizadas as instituições educativas, tem uma grande área verde no seu entorno e isso favorecera as práticas didáticas ambientais.

Pires e Faria (2010), desenvolveram um estudo de investigação onde verificaram de que maneira se realizava a construção dos PPPs e como se incorporava as propostas de EA nos projetos de uma escola da rede estadual, do município de Cruzeiro do Sul - AC, tendo como alvo o ensino fundamental. Após análise documental, observações informais e aplicação de questionário, verificou se pelo estudo que a EA vinha sendo trabalhada de forma isolada a exemplo de realizações de passeatas, passeios, visitas e campanhas.

Ainda conforme os autores o estudo era motivado pela percepção da relevância que a EA assume no desenvolvimento dos PPPs, seus dados ressalvam que na implementação do projeto o grupo participante mantinha foco em inserir a EA de forma isolada apenas para contempla-la. Outra observação dos pesquisadores era de que apenas os professores contribuíam para a formulação dos PPPs, sendo excluída a participação de outros segmentos da escola, da sociedade e dos pais. Na conclusão do estudo fica claro que mesmo tendo a EA presente nos PPPs da escola, ela não vem sendo trabalha de forma multidisciplinar e transversal (PIRES, FARIA, 2010).

Saraiva, Nascimento e Costa, 2008, em sua pesquisa que abordou a prática pedagógica do ensino de EA em três escolas públicas da cidade de João Câmara -RN, evidenciou-se que a 
maioria dos docentes tinham consciência das facilidades de se trabalhar a EA em suas disciplinas, entretanto carece de um PPP que contemple a temática nas escolas pesquisadas.

Em estudo semelhante Ferrari e Zancul (2010), descrevem e analisam dados sobre as propostas e as atividades de EA mencionadas nos PPPs de escolas municipais de Ensino Fundamental na cidade de Araraquara -SP, apontaram que os PPPs de sete, das oito escolas abrangiam conteúdos e atividades ambientalmente educativas, entretanto a ressalva dos autores que os PPPs não contemplavam uma visão holística sobre temática ambiental de forma transversal. Nas suas conclusões os autores visam contribuir nos debates que impulsionem as práticas pedagógicas ambientais e destacam as prioridades de uma construção dos PPPs de forma democrática e participativa.

Ferrari e Zancul (2008), ao analisarem os PPPs de oito escolas de Ensino Fundamental da Rede Municipal de Araraquara- SP, tinham perspectivas de encontrar documentos com orientação baseadas em fundamentos teórico-metodológicos claros referentes ás didáticas ambientais, entretanto os autores dissertam ter encontrado os PPPs, modelados a partir de muitos recortes, não sendo possível que pudessem identificar um eixo orientador das práticas pedagógicas na temática da EA.

Ainda na mesma pesquisa os referidos autores mencionam ter encontrado nos PPPs analisados, indícios de três práticas pedagógicas relacionadas a EA, sendo elas: visitas monitoradas a centros de EA e parques zoobotânicos; um projeto socioambiental instituído como "Aprendendo com a Natureza" e o Programa Nacional de Conservação de Energia Elétrica, projeto relativo à conservação da energia elétrica. Os coordenadores pedagógicos dessas instituições reconheciam a necessidade de reelaborar novos projetos que viessem a contemplar, de forma mais adequada, os aspectos de EA.

\section{Metodologia}

O presente trabalho caracteriza-se como uma análise crítica qualitativa. Conforme Almeida et al (2009, p. 4), "A análise documental busca identificar informações factuais nos documentos a partir de questões e hipóteses de interesse". Para Helder (2006. p. 3), "A técnica documental vale-se de documentos originais, que ainda não receberam tratamento analítico por nenhum autor". Sendo assim, os documentos analisados por essa pesquisa são Projetos Políticos Pedagógicos do ensino fundamental de 03 escolas públicas do município de São Miguel do Oeste - SC. Pela análise documental foi levantado a existência das temáticas ambientais, o enfoque da EA existente, e como suas transversalidades e interdisciplinaridades vêm sendo trabalhadas nos projetos.

Os PPPs dessas instituições educativas foram minuciosamente analisados empregando uma visão crítica construtiva a fim de se obter uma resposta sólida e ampla de como a EA está inserida nos PPPs das séries do ensino fundamental dessas escolas públicas, identificando a presença de interdisciplinaridade e transversalidade do tema.

Pesquisas qualitativas segue a rigor um plano previamente o estabelecido (NEVES, 1996). Neste trabalho a metodologia consistiu-se nos seguintes procedimentos: as análises documentais dos PPPs das unidades escolares e um questionário respondido por um representante da escola (coordenador pedagógicos, diretor ou assessor) baseado no trabalho de Trajber e Mendonça (2006), ambos se fundamentando no objetivo de responder as seguintes questões pertinentes:

- O que engloba a proposta pedagógica para EA?

- Quais são as referências e fundamentos teóricos?

- Os modelos, meios, recursos e instrumentos a serem utilizados na EA?

- Como os trabalhos em EA são ou devem ser realizados? 
- As propostas dos PPPs englobam a transversalidade da EA?

- As propostas dos PPPs se fundamentam na interdisciplinaridade da EA?

\subsection{As escolas lócus da pesquisa}

As escolas lócus da pesquisa estão localizadas no município de São Miguel do Oeste, Santa Catarina, município com uma população de 38.162 mil habitantes, segundo dados do Instituto Brasileiro de Geografia e Estatística (2013), sendo 32.282 de pessoas alfabetizadas. São Miguel do Oeste possui uma área territorial de $234,055 \mathrm{~km}^{2}$ e destaca-se pela produção agrícola e agroindustrial. O município integra os 118 municípios da mesorregião do oeste catarinense.

No âmbito da educação São Miguel do Oeste conta com 23 escolas de ensino fundamental, sendo elas sete escolas públicas estaduais, doze públicas municipais, três particulares, um instituto federal de educação tecnológica. Segundo último senso escolar do IBGE, 2012, foram 4.321 alunos matriculados no ensino fundamental no ano letivo de 2012, onde 3.674 alunos inseridos na educação pública e 647 em escolas privadas do município. Dentre as escolas públicas municipais de ensino fundamental o estudo desenvolveu-se nas três maiores instituições educativas, sendo elas a EEB São Miguel, EEB Prof. Jaldyr B. F. da Silva e a EEB Alberico Azevedo.

\subsubsection{E. E. B. São Miguel}

A Escola de Educação Básica São Miguel é a principal instituição de educação pública estadual do município. Dispõem de educação do $3^{\text {o }}$ ano das séries iniciais aos anos finais do ensino médio. A escola funciona nos três turnos (matutino, vespertino e noturno), totalizando em torno de 650 alunos.

$\mathrm{Na}$ sua infraestrutura a escola dispõe de biblioteca com exemplares de livros e revistas, laboratório e ginásio de esportes coletivos. A instituição desenvolve atividades complementares, projetos que visam à diversidade, a inclusão de pessoas com deficiência, a EA com Projeto de Preservação do Meio Ambiente, Programa de Controle do Peso Corporal para Crianças e Adolescentes, projetos voltados ao incentivo à leitura, literatura e escrita, Cinema na Escola, Feira da Ciência e Conhecimento, Festival da canção, Participação nos Jogos abertos de Santa Catarina para pessoas com deficiência, entre outros.

\subsubsection{E. E. B. Prof. Jaldyr B. F. Da Silva}

Escola de Educação Básica Professor Jaldyr Bhering Faustino Silva dispõe de turmas da préescola e ensino fundamental nos turnos matutino e vespertino, a turmas conclusivas do ensino médio nos turnos matutino e noturno. Na escola ainda se localiza o polo da Universidade Aberta do Brasil (UAB), a escola recentemente foi reconstruída e suas dependências atuais dispõe de salas de aulas modernas, biblioteca, ginásio de esporte.

\subsubsection{E. E. B. Alberico Azevedo}

A Escola de Educação Básica Alberico Azevedo atende a educação das séries iniciais do ensino fundamental ao ensino médio completo, disponibilizando aulas nos três turnos matutino, vespertino, totalizando em torno de 600 alunos matriculados no ano letivo de 2014 .

Nas suas dependências físicas a escola conta com ginásio de esportes, biblioteca, sala de informática, sala de vídeo e infraestrutura básica escolar. A escola tem em estudo o desenvolvimento para a implantação de um projeto que atendera o ensino médio profissionalizante. 


\section{Resultados}

\subsection{Análise dos Projetos Políticos Pedagógicos}

Os Projetos Políticos Pedagógicos das instituições foram recentemente alterados, modificados e revisados para a vigências do ano letivo de 2014, todos trazem a descrição detalhada e características físicas, administrativas e pedagógica de cada instituição.

Os PPPs das escolas enfatizam as principais dificuldades apresentadas pelos alunos, citando como obstáculos na construção do conhecimento a falta de leitura, a exclusão tecnológica, dificuldades no acesso aos meios de informações fora do ambiente escolar e aos bens culturais, à dificuldade econômica e salientam que os alunos do ensino noturno são alunos na sua maioria trabalhadores em tempo integral.

\subsubsection{PPP da E. E. B. São Miguel}

A Escola de Educação Básica São Miguel tem seu PPP desenvolvido com o envolvimento e participação do corpo docente, discente, comunidade escolar e órgãos representativos da comunidade (Conselho Deliberativo Escolar, Associação de Pais e Professores (APP) - Clube de Mães e Grêmio Estudantil). O PPP salienta tal necessidade da escola em trabalhar com uma maior eficiência a integração entre os componentes curriculares, suprindo assim os quesitos básicos pedagógicas de inúmeros temas, desenvolvendo-os de forma coletiva e interdisciplinar.

- O que engloba a proposta pedagógica para EA?

Engloba a proposta de se trabalhar a EA no currículo de ciências em um projeto extracurricular.

- Quais são as referências e fundamentos teóricos?

O referencial de trabalho da EA no currículo de Ciência orienta os seguintes tópicos de trabalho: Meio/Ambiente e importância para a vida no planeta Poluição, lixo, desmatamento Reciclagem e Saneamento Básico, Produção e consumo consciente.

- Os modelos, meios, recursos e instrumentos a serem utilizados na EA?

O PPP não traz modelos de trabalhos, não se refere especificamente em algum método ou algum evento, entretanto menciona o desenvolvimento de um projeto de preservação ambiental e feira de Ciências aonde os alunos têm a oportunidade de buscar projetos e práticas ambientalmente sustentáveis.

- Como os trabalhos em EA são ou devem ser realizados?

O PPP traz um projeto denominado Programa Educação Ambiental - Com-Vida, aonde a participação de docente e discentes, contribui para visão da dinâmica ambiental, trazendo vivências, pesquisas e exposição de saberes, práticas compartilhadas e ainda a organização de uma Conferência de Meio Ambiente na Escola.

- As propostas dos PPPs englobam a transversalidade da EA?

Sim, a proposta do PPP da escola se refere a EA como tema a ser trabalhado de forma transversal como seguintes temas Meio/Ambiente e importância para a vida no planeta Poluição, lixo, desmatamento, Reciclagem e Saneamento Básico.

- As propostas dos PPPs se fundamentam na interdisciplinaridade da EA?

O PPP não apresenta qualquer menção a EA ou meio ambiental no currículo de outras matérias, o trabalho de EA apenas está inserido no currículo de ciências, apesar de trabalhar o tema de Meio Ambiente na matéria de Geografia não menciona os conceitos de reeducação socioambiental. 
Em seu PPP a E. E. B. Jaldyr B. F. da Silva salienta a falta de envolvimento e comprometimento dos pais com a dinâmica escolar, ainda ressalva que há uma significativa migração de alunos durante o ano letivo. O projeto é desenvolvido na base de formar cidadãos socialmente críticos e capazes de agir de forma construtiva e intelectual frente ás necessidades cotidianas, comunitárias e profissionais.

Ainda no PPP é considerado a importância do conhecimento enraizado e o cultural que o aluno traz para a sala de aula, voltando-se na iniciativa de que seja conduzido em uma melhor conviç̧ão do conhecimento, sua filosofia social na escola é proporcionar o desenvolvimento integral dos alunos para a sua transformação e construção com base na realidade social vivida.

- O que engloba a proposta pedagógica para EA?

A proposta da escola refere-se a projetos nível a escolar, incentivos as boas práticas com o meio ambiente, feira de ciências e orientação a toda a comunidade escolar a ações de conservação ambiental, os temas a serem trabalhados como currículos básicos nas séries do ensino fundamental.

- Quais são as referências e fundamentos teóricos?

Não há descrição de alguma referência ou fundamento teórico no PPP, para se basear as atividades englobadas na EA.

- Os modelos, meios, recursos e instrumentos a serem utilizados na EA?

Os meios da construção do conhecimento ambiental se baseiam em projetos de vivências, utilizando formas didáticas possíveis, literatura, vídeos, palestras, visitas técnicas, programas municipais e dias comemorativos.

Não trazendo modelos descritivos a serem seguidos.

- Como os trabalhos em EA são ou devem ser realizados?

Através de conteúdos mínimos a serem trabalhados nos currículos do ensino fundamental, mencionando os citados: conscientização sobre recursos naturais e ambientais, gincana ecológica, caminha ecológica.

A EA também é trabalhada na feira de ciências, no projeto em desenvolvimento referente à material reciclável e coleta seletiva do lixo.

- As propostas dos PPPs englobam a transversalidade da EA?

Sim o PPP traz menção sobre se trabalhar todos os assuntos de forma transversal, até mesmo através de uma gincana ecológica, jogos ambientais. O PPP ainda um projeto de leitura que tem como objetivo específico de se trabalhar temas transversais citando especificamente o meio ambiente.

- As propostas dos PPPs se fundamentam na interdisciplinaridade da EA?

Sim, além de estar mencionado em todo o currículo do ensino fundamental não especificando a matéria a qual cabe sua competência a EA o PPP impõe o objetivo de realização de trabalhos interdisciplinares, não sendo especifico nem detalhando o procedimento.

\subsubsection{PPP da E. E. B. Alberico Azevedo}

O Projeto Político Pedagógico da Escola de Educação Básica Alberico Azevedo apresenta a visão da escola em desenvolver trabalhos focados na ética e cidadania nas mais diversas formas didáticas, mais especificamente no ensino fundamental. Visa proporcionar aos alunos uma maior compreensão do sujeito em si, suas relações sociais, com a natureza, com seu corpo, com sua cultura e com os aspectos políticos. O posicionamento do PPP da instituição é que suas 
ações educativas valorizem as relações e interações sociais vividas pelos alunos de forma que desperte sua visão holística.

- O que engloba a proposta pedagógica para você?

O PPP menciona poucas propostas de se trabalhar a EA referindo-se em um projeto extracurricular e no currículo de ciências e geografia de forma pouco detalhada.

- Quais são as referências e fundamentos teóricos?

Os referenciais de trabalho da EA no currículo nos componentes curriculares não mencionam diretamente o tema e sim de forma geral o conhecimento de meio ambiente, impacto ambiental, consumo de recursos naturais e entre outras questões relacionadas as ciências ambientais, no entanto não se refere a uma visão sustentável.

- Os modelos, meios, recursos e instrumentos a serem utilizados na EA?

Não, o PPP não traz referências a modelos de trabalhos, não descreve especificamente algum método ou evento.

- Como os trabalhos em EA são ou devem ser realizados?

Não há menção alguma sobre a forma de ser trabalha no ano letivo.

- As propostas dos PPPs englobam a transversalidade da EA?

O PPP menciona a necessidade de se trabalhar toda a educação de forma transversal.

- As propostas dos PPPs se fundamentam na interdisciplinaridade da EA?

Há referências em se trabalhar os conteúdos curriculares de forma interdisciplinar, não sendo específica sua abordagem na EA.

\subsection{Questionário Aplicado}

Os questionários aplicados nas instituições tinham como objetivo complementar as informações sobre a visão e o histórico da EA das escolas pesquisadas., Não sendo foco do presente estudo, não serão detalhados, apenas será apresentado um síntese detalhada sobre o perfil dos educadores (diretores ou coordenadores pedagógicos) aos quais dispuseram a colaboração na construção do conhecimento da dinâmica e do contesto da EA das escola de São de Miguel do Oeste -SC. Esse questionário traz perguntas que primeiramente caracterizam o perfil profissional do educador, posteriormente enfatiza o histórico e o enfoque na EA da instituição educativa e finaliza traçando a visão escolar frente ao tema sustentável.

\subsubsection{Questionário aplicado a E. E. B. São Miguel.}

O questionário foi respondido pela coordenadora pedagógica da escola, a senhorita Ana Mara Meo (nome fictício), professora de Educação Artísticas com especialização na área. Segundo a docente a E. E. B. São Miguel desenvolve a EA há mais de 10 anos, tendo seu início a partir de iniciativas dos próprios professores, por interesse dos alunos, pelas políticas educacionais e por projetos ambientais na comunidade. Nesse sentido a escola tem a visão de que todos os conceitos da EA têm sua importância, ainda segundo a coordenadora o tema vem sendo desenvolvido na escola através de projetos, tema transversal, nos currículos de todas as disciplinas e no PPPs, quando desenvolvidos nos projetos a temática é trabalhada de forma interdisciplinar, integrando-se com o PPP e focando-se em ações de múltiplas áreas, envolvendo por meio de iniciativas e participação toda a comunidade escolar.

Para a escola os principais temas a serem tratados na EA é água, problemas urbanos, qualidade de vida e lixo reciclável, envolvendo todas as formas de trabalhos nas disciplinas, aonde toda a comunidade escolar tem sua participação nessa gestão, os professores por sua vez fazem sua formação na EA pela secretaria da educação do estado. A escola atua de toda forma 
possível para formação contínua dos docentes em EA e interagem com a comunidade através de palestras e participação em eventos relacionados ao meio ambiente.

\subsubsection{Questionário aplicado a E. E. B. Jaldyr B. F. da Silva.}

$\mathrm{Na}$ escola Jaldyr a responsável pelas informações no questionário aplicado foi a senhorita Maria Mendes (nome fictício), assessora da direção, formada em Ciências Biológicas, com especialização na área. Ela leciona matérias nas áreas de Ciências Naturais. Sobre as informações respondidas no questionário, a EA é desenvolvida na escola por meio de projetos, que são realizados a partir da integração entre duas ou mais disciplinas intercalando a temática com a matéria a ser trabalhada conforme o PPP. Isso também acontece por meio de uma atuação conjunta da comunidade escolar. A iniciativa desses projetos se deu por parte de um grupo de docentes juntamente com a direção da escola, seu desenvolvimento envolve a coletividade escolar, tendo como seus principais temas a água, poluição e saneamento básico, hortas e pomares, problemas urbanos e lixo e reciclagem.

Segundo Maria, a EA na escola envolve a articulação entre elementos teóricos e práticos incorporados em uma discussão, enfoque na solução do problema, a vinculação das questões socioambientais com o conteúdo formal e mais aproximado de matérias como Biologia e Geografia. E escola atua na formação de educadores ambientais através do acesso dos professores a informação ambiental, a interatividade com a comunidade ocorre em alguns casos. Ainda segundo a docente, todos os fatores estão contribuindo para o trabalho da EA na escola, entretanto apenas foi possível de se perceber mudanças nas práticas sustentáveis pelo maior número de trabalhos apresentados na feira de Ciências relacionados ao tema e como principais dificuldades no desenvolvimento da temática a assessora indica que todos os itens apontados no questionário estão presente na escola.

\subsubsection{Questionário aplicado a E. E. B. Alberico Azevedo}

Quanto ao questionário da escola Alberico Azevedo, ele foi inteiramente respondido pela Coordenadora pedagógica Luisa Halus (nome fictício), pedagoga com especialização. A coordenadora relatou que a escola vem trabalhando a EA há mais de 7 anos em seus conteúdos, iniciativa essa dada pelas diretrizes da secretaria estatual e desde então a escola foca a importância a consciência socioambiental, o desenvolvimento de forma sustentável e a preservação, proteção e zelo pelos recursos naturais. Em suas respostas ela deixa claro que a escola trabalha o tema na forma de projetos nas áreas das Ciências Naturais, sendo que esses projetos acontecem por meio da atuação da comunidade escolar, sua iniciativa contou com a participação dos professores, da direção e dos alunos da instituição, aonde os projetos priorizam os temas relacionados aos recursos naturais, a biodiversidade, a saúde e diversidade social.

Conforme informação da pedagoga, a EA na escola Alberico Azevedo envolve o enfoque na solução de problemas, a articulação dos elementos teóricos e práticos, o vínculo das questões socioambientais e os conteúdos mais relacionados as disciplinas de Biologia e Geografia, sua gestão tem a participação do grupo escolar interno. Quanto a formação contínua dos docentes na área da EA, ela ocorre por meio de curso oferecidos pela Gerência Regional de Educação, sendo esse juntamente com a presença de professores qualificados no assunto, um dos fatores que contribuem a inserção do conteúdo ambiental na escola.

A pedagoga ainda contribuiu para a pesquisa salientando que já é possível se perceber uma significativa mudança na vivência interna da escola, influenciada segunda ela pela inserção do tema nos conteúdos, o que também ocasionou mais produção de trabalhos na feira de ciências, 
entretanto a maior dificuldade ainda é a conscientização dos pais dos alunos nas questões pertinentes a sustentabilidade.

\section{Discussões}

A análise crítica dos Projeto Políticos Pedagógicos revelou uma problemática no modo que as escolas tendem a trabalhar a EA, mesmo estando presente nos referidos documentos norteadores das escolas, de uma forma mais detalhada e aprofundada em umas menos em outras, a proposta pedagógica em que a EA está inserida se dá principalmente como atividade extra curricular, em forma de projetos que nem sempre podem ser trabalhados durante todo o ano letivo, pois esses projetos extra curriculares são eventos pontuais e em sua maioria específicos. A EA não está presente durante todo o ensino fundamental, nem mesmo nos currículos das matérias mais específicas como geografia e biologia.

Segundo Silva (2009), as atividades referentes a EA devem estar no centro dos PPPs das escolas, só assim proporcionam que os alunos tenham a oportunidade de evoluir na sensibilização a respeito dos problemas ambientais, buscando formas alternativas e sustentáveis, conduzindo pesquisas no ambiente urbano, relacionando fatores socioambientais, holísticos e históricos com fatores políticos, éticos e de cidadania.

No trabalho ainda se observou uma significativa deficiência em se ter referenciais teóricos, livros ou manuais para que os docentes possam seguir como modelos didáticos e aonde se basear para o desenvolvimento de ações pedagógicas sustentáveis. Algumas escolas ainda tentam trazer possíveis modelos a se trabalhar o tema, como por meio de feiras de ciências como nas escolas Jaldyr B. F. da Silva e na escola São Miguel, palestra, vídeos, ações junto à comunidade como o programa "Com Vida" da E. E. B. São Miguel, gincanas e até mesmo uma conferência sobre o meio ambiente na escola.

Silva (2009) reflete que a aprendizagem da EA será mais significativa quando a atividade planejada estiver adaptada concretamente às situações da vida real da comunidade, da vivência dos alunos ou dos professores. Segundo o autor as ações pedagógicas de EA que empregam o uso e confecção de cartilhas, cartazes, folders e outros recursos do gênero vêm sendo meio de desperdício de recursos financeiros públicos e fracassos lamentáveis. Os erros vêm se repetindo: planeja-se sem o conhecimento devido do perfil socioambiental da comunidade a ser envolvida no projeto.

Ainda para Ferrari e Zancul (2012), é essencial que sejam constituídas diretrizes da EA que sirvam como base teórica para a rede pública municipal e que ao mesmo proporcionem e incentivem a autonomia e a dinâmica de cada unidade escolar.

Quanto a transversalidade e interdisciplinaridade de certo modo ambas estão mencionadas de forma geral nos trabalhos didáticos ao longo do ano letivo, apenas no PPP da E. E. B. São Miguel, o PPP se refere especificamente em um trópico "2.10 Temas transversais", no que consta a EA como tema a ser trabalhado de forma transversal nos currículos do ensino fundamental, porém não detalhando a forma que essa ação ocorrera. Quanto à base de trabalho interdisciplinar a EA não é diretamente mencionada e está presente em todas as matérias.

Frente à discussão Pereira, Bittar e Grigoli (2005) relatam que o Ministério da Educação propôs e elaborou Parâmetros Curriculares Nacionais (PCN), no qual considera o Meio Ambiente como um Tema Transversal a ser trabalhado, devendo estar integrado a todos níveis de ensino, numa relação de transversalidade, de modo que incorporem toda a prática pedagógica proporcionando uma visão holística das questões ambientais. Assim os PCN tratam a transversalidade e a interdisciplinaridade como uma perspectiva crítica, o que difere uma da outra é que a interdisciplinaridade abrange uma abordagem epistemológica dos objetos de 
conhecimento, enquanto a transversalidade diz respeito principalmente à dimensão da pedagógica.

O parecer dos questionários não reflete o posicionamento da EA que se encontra na pratica inseridos nos PPPs, segundo os profissionais educadores que responderam esses questionários a EA vem sendo amplamente trabalhada de forma interdisciplinar e transversal, como salienta a coordenadora da escola São Miguel em suas respostas o tema vem sendo desenvolvido na escola através de projetos, nos currículos de todas as disciplinas e no PPPs, quando desenvolvidos nos projetos a temática é trabalhada de forma interdisciplinar, integrando se com o PPP da sua instituição.

Ainda constatou se pelos questionários que nem sempre são sentidas mudanças na consciência ambiental da comunidade escolar, segundo a assessora de direção da escola Jaldyr B. F. da Silva, apenas foi possível de se perceber mudanças nas práticas sustentáveis pelo maior número de trabalhos apresentados na feira de Ciências relacionados ao tema. As respostas demonstraram ainda uma severa dificuldade em se trabalhar a EA nas escolas, os temas como falta de integração entre os docentes e direção, a dificuldade do tema frente à comunidade, a falta de recursos matérias e humanos qualificados, falta de tempo e conflitos de interesse, estão sendo um impasse no desenvolvimento da EA nessas escolas.

O que pode se concluir da análise documental dos PPPs é que as ideias acerca da EA parecem tender para o paradigma antropocêntrico. Esse paradigma conforme Reigota (2001) é uma concepção falha da questão ambiental educacional, pois somente evidenciar a utilidade dos recursos naturais para a sobrevivência do ser humano não basta. Ao encontro dessa questão Medina e Santos (2008) destacam que a EA não se trata apenas de lecionar sobre a natureza, mas sim de educar "para" e "com" a natureza, modelando cidadãos que compreenderam como agir corretamente frente os grandes problemas das relações do homem com o ambiente, é uma educação para ensinar o ser humano sobre seu papel na biosfera, instituído as prováveis corretas relações entre a sociedade e a natureza nos processos de desenvolvimento, sobrevivência e cotidiano adotados pelos diferentes grupos sociais.

\section{Considerações Finais}

Na objetividade desse trabalho de conhecer e levantar informação sobre as formas que escolas abordam, trabalham e orientam a EA nos PPPs, demonstrou-se que o tema está distante de ser considerado um dos temas principais dos projetos e que ainda não vem sendo detalhadamente referenciado com informações norteadoras para o desenvolvimento da prática educacional durante o ano letivo. A relevante falta de referenciais teóricos para se trabalhar o tema aumenta a dificuldade para "romper" com o pensamento antropocêntrico, no qual vê o homem como o centro do universo e ofusca a visão holística de se compreender o meio ambiente.

Pelo que se pode observar na análise teórica dos projetos, a transversalidade e a interdisciplinaridade não estão efetivamente presentes na prática, nem mesmo descritos nos currículos das disciplinas, uma vez que há PPPs que não mencionam a obrigatoriedade de se trabalhar o tema dentro de seu programa didático. Suas atividades poderiam ser mais abrangentes no ano letivo, tendo em vista que EA é uma ferramenta capaz de transformar o paradigma do pensamento ambiental, crucial na formação de novos cidadãos socioambientalmente comprometidos com a qualidade de vida, conscientes com a necessidade de preservação de recursos naturais, da biosfera e das necessidades das gerações futuras.

O presente estudo propõe uma reformulação dos PPPs, inserindo a temática da EA em todos os currículos das disciplinas, de modo que os temas poderiam ser trabalhados tendo relação com matéria escolar, como em matemática através de cálculos de consumo de recursos naturais, 
na educação artística, utilizando material reciclado para suas expressões artísticas e manifestações culturais, no português através de literaturas ou textos que abordem o tema, entre outros exemplos. Assim vislumbra-se a possibilidade de empregar na prática a transversalidade do assunto e proporcionar de fato que a interdisciplinaridade realmente ocorra dentro das salas de aulas, tendo como base uma visão mais holística, ou seja trabalhando a importância não só dos recursos naturais, mas considerando as relações ecológicas, a biodiversidade, a dinâmica e a interação nos ecossistemas, a importâncias do fluxo de energia nos trópicos, a saúde ambiental, a qualidade de vida e a garantia dos recursos necessários para as gerações futuras.

Por fim, enfatiza-se o quanto seria benéfico para educação formal a implantação geral da escola em tempo integral, onde falta de tempos para se trabalhar a visão sustentável daria lugar a um maior tempo para se trabalhar com oficinas e práticas aprofundadas em ações, ferramentas, projetos e planejamento favoráveis ao meio ambiente, garantido que não somente a visão antropocêntrica seja trabalhada na EA.

O presente trabalho ainda coloca a possibilidade de se incentivar que sejam criadas organizações não governamentais (ONGS), através da sociedade ou até mesmo dentro das instituições de ensino superior, para trabalhar a EA junto às escolas ou através de desenvolvimento de material teórico e projetos-modelo a serem trabalhados na educação formal.

Torna-se necessário, para uma visão mais abrangente e comprometedora de como a EA vem sendo trabalhada nos Projetos Políticos Pedagógicos das escolas públicas, uma pesquisa mais ampla e com maior abrangência regional, presenciando as aulas teóricas para consolidar as respostas obtidas nos questionários.

\section{Referências}

A Carta da Terra. Última versão em português. Um programa da UNESCO. Maio 2000. Disponível em $<$ boasaude.uol.com.br/lib/ShowDoc> Acesso em: 19 jun. 2013.

ALMEIDA, C. D. et al. Pesquisa documental: pistas teóricas e metodológicas. Revista Brasileira de História \& Ciências Sociais, $\quad$ v. $\quad 1$, p. $\quad 1-15, \quad 2009$. Disponível em < http://www.rbhcs.com/index_arquivos/Artigo.Pesquisa\%20documental.pdf > Acesso em: 12 mai. 2014.

ANDRADE, T.H.N; RIBEIRO, M.L.N. A questão política das mudanças climáticas. Resv. Bras. de Ciência, Tecnologia e Sociedade. V2, n1. Pag 211-225, jan/jun, 2011. Disponível em < http://www.revistabrasileiradects.ufscar.br/index.

php/cts/article/viewFile/137/59 > Acesso em: 22 jun. 2013.

ARAÚJO Fabiane M.; SANTOS Elizabeth C. Educação Ambiental E A Prática Da Transversalidade Na Formação De Professores: Reflexos No Ensino Básico. Encontro Nac. de Pes. Em Educação em Ciências. Florianópolis. nov. 2009. Disponível em < http://posgrad.fae.ufmg.br/posgrad/viienpec/pdfs/686.pdf > Acesso em: 22 dez. 2013

BRASIL. Constituição Federal, Código Civil (2002). Código do Processo Civil, Código Penal. Código de Processo penal e Legislação complementar. Barueri: São Paulo: Manole, 2003.

BRASIL. Lei n. 9.396, de 20 de dezembro de 1996. Estabelece as diretrizes e bases da educação nacional. Diário Oficial [da República Federativa do Brasil], Brasília, DF, n. 248, 23 dez. 1996, seção 1, p. 27833. 
BRASIL: MINISTÉRIO DO MEIO AMBIENTE. Agenda 21 Brasileira: resultado da Consulta nacional / Comissão de Políticas de Desenvolvimento Sustentável e da Agenda 21Nacional. 2. ed. Brasília, 2004.

BRASIL. Presidência da República. Lei no 9.795, de 27 de abril de 1999. Dispõe sobre a educação ambiental, institui a Política Nacional de Educação Ambiental e dá outrasprovidências. Diário Oficial da União, Brasília, DF, 28 abr. 1999. Disponível em: <http://www.planalto.gov.br/ccivil>. Acesso em: 29 jun. 2013.

BRASIL: Secretaria de Educação Fundamental. Parâmetros curriculares nacionais: meio ambiente / Secretaria de Educação Fundamental. - Brasília: MEC/SEF, 1999d.

BRUGGER, Paula. Educação ou adestramento ambiental? Florianópolis: Obra Jurídica, 2004.

COIMBRA, Audrey de Souza. Interdisciplinaridade e Educação Ambiental: integrando seus princípios necessários. Revista. Eletrônica do Mestrado. Educação. Ambiental. ISSN 1517-1256, Volume 14, Janeiro a junho de 2005.

CÓRDULA, Eduardo B. L. Educação Ambiental Integradora (EAI): Unindo saberes em prol da consciência ambiental sobre a problemática do lixo. Rev. Bra. De Edu. Ambiental, vol. 5 num.01, 2010.

COSTA, Aurora M. F. C. Educação Ambiental na Alfabetização de Adultos: do Cotidiano para a Sala de Aula, da Sala de Aula para a Vida. Anais do $2^{\circ}$ Congresso Brasileiro de Extensão Universitário Belo Horizonte, 2004. Disponível em: < https://www.ufmg.br/congrext/Meio/Meio49.pdf>. Acesso em: 29 jun. 2013.

DIAS. Genebaldo Freire. Educação ambiental: princípios e práticas. 8.ed. São Paulo: Gaia, 2003. 551p.

FERRARI, Alexandre. H.; ZANCUL, Maria. C. S. A educação ambiental nos projetos político-pedagógicos das escolas municipais de ensino fundamental da cidade de Araraquara/SP. Rev. Eletrônica Mestr. Educ. Ambient., Rio Grande, RS, v. 25,n. 2, 2010. Disponível em: < http://www.seer.furg.br/remea/article/view/3368>. Acesso em: 30 dez. 2013.

GIDDENS, A. Introduction \& A Returno To Planning? In: The politics of climate change. Cambridge: Polity, 2009.

GUIMARÃES, Mauro. A dimensão ambiental na educação. Campinas (SP): Papirus, 2002.

GUIMARÃES, Mauro. Educação ambiental crítica. In: LAYRARGUES, Philippe Pomier (Coord.). Identidades da educação ambiental brasileira. Brasília: Edições MMA, 2004. p.25-34. Disponível em $<$ http://www.aja.org.br/publications/livro_ieab. pdf>. Acesso em: 30 jun. 2013.

HELDER, R. R. Como fazer análise documental. Porto, Universidade de Algarve, 2006.

ISAIA, Enise. M. B. I. Reflexões e práticas para se desenvolver educação ambiental na escola. 2. ed. Santa Maria: Ed. UNIFRA/IBAMA, 2001.

JACOBI, Pedro. Educação Ambiental, Cidadania E Sustentabilidade. Cadernos de Pesquisa, n. 118, p. 185205. Mar. 2003. 
KIST, Anna. C. F. A água numa perspectiva crítica da Educação Ambiental: Uma análise a partir da III conferência Nacional Infanto-Juvenil pelo meio ambiente. (monografia de especialização) Santa Maria: UFSM, 2009. 91f.

KRUGUER, Eduardo L. Uma abordagem sistêmica da atual crise ambiental. Desenvolvimento E Meio Ambiente. Curitiba, n.4, p.38, 2001. Disponível em: <https://www.google.com.br/url?F\%2Fojs.c3sl.ufpr.br\%2Fojs2\%2Findex.php\%2Fmade\%2Farticle\%2Fdownloa d\%2F3038\%2F2429\&ei=Wo_YUaihHfSC0QGNnoCYBQ\&usg=AFQjCNFeJCngaf5hY4KU1jXxnz3HpgV6Q\&sig2=vPzo7meObEr4mKMmAdYcQA >. Acesso em: 02 jul. 2013.

LEFF, E. 2001. Saber ambiental: sustentabilidade, racionalidade, complexidade, poder. Petrópolis, RJ: Vozes, 343 p.

LEITE, A. L. T. de A.; MEDINA, N. M. Educação ambiental: curso básico a distância: Educação e Educação Ambiental II. 5 v. 2 ed. Brasília: MMA, 2001.

LUCK, Heloísa. Pedagogia interdisciplinar: fundamentos teórico-metodológicos. 11 ed. Petrópolis, RJ: Vozes, 2003.

MIRANDA, Fátima. H. F; MIRANDA, José. A; RAVAGLIA, Rosa. Abordagem Interdisciplinar em Educação Ambiental. Revista Práxis. Ano II, n4 - ago. 2010. Disponível em < http://web.unifoa.edu.br/praxis/numeros/04/11.pdf >. Acesso em: 30 dez. 2013.

MEDINA, Naná M. Educação ambiental: uma metodologia participativa de formação. 3. ed. Petrópolis: Vozes, 2003.

MENEZES, CÁSSIA M. V. M. C. Educação Ambiental: a criança como agente multiplicador. Monografia (MBA em Gestão Ambiental e Prática de Sustentabilidade) Escola de Engenharia Mauá do Centro Universitário do Instituto Mauá de Tecnologia. São Caetano do Sul - SP, 2012.

NEVES, J. L. Pesquisa qualitativa - características, usos e possibilidades. Caderno

de pesquisas em administração, São Paulo, v. 1, no 3, 2o sem. 1996. Disponível em: < http://www.dcoms.unisc.br/portal/upload/com_arquivo/pesquisa_qualitativa_caracteristicas_usos_e_possibili dades.pdf >. Acesso em: 11 mai. 2014.

PEREIRA, Kely A. B. P.; BITTAR, Michelle; GRIGOLI, Josefa A. G. G. A Transversalidade E A Interdisciplinaridade Em Educação Ambiental: Uma Reflexão Dentro Da Escola. Disponível em: < http://www.histedbr.fae.unicamp.br/acer_histedbr/jornada/jornada7/_GT4\%20PDF/A\%20transversalidade\%2 0e\%20a\%20interdisciplinaridade\%20em\%20educa\%E7\%E3o\%20ambiental\%20GT4.pdf $>$. Acesso em: $30 \mathrm{dez}$. 2013.>. Acesso em: 27 dez. 2013.

PIRES, Pierre A. G.; FARIA, Wendell F. A Educação Ambiental E O Projeto Político-Pedagógico: Articulações No Cotidiano Em Uma Escola Estadual De Cruzeiro Do Sul/Acre. REU, Sorocaba, SP, v. 36, n. 3, p. 201-227, dez. 2010. Disponível em http://periodicos.uniso.br/ojs/index.php?journal=reu\&page=article\&op=view\&path $\% 5 B \% 5 \mathrm{D}=507 \mathrm{pdf}>$. Acesso em: 30 dez. 2013.>. Acesso em: 27 dez. 2013.

SANTA CATARINA (Estado). Proposta de Curricular de Santa Catarina: Educação Infantil, Ensino Fundamental e Médio. Secretaria de Estado de Educação e do Desporto; COGEN, 1998. 120 p. 
SANTOS, Elizabeth C. Transversalidade e Áreas Convencionais. UEA Edições. Editora Valer, 2008.

SARAIVA, Vanda M.; NASCIMENTO, Kelly R. P.; COSTA, Renata K. M. A Prática Pedagógica Do Ensino De Educação Ambiental Nas Escolas Públicas De João Câmara - RN. Holos, Ano 24, Vol. 2. 2008. Disponível em < http://web.unifoa.edu.br/praxis/numeros/04/11.pdf >. Acesso em: $30 \mathrm{dez} .2013$.

SILVA, M. A. Do Projeto político do Banco Mundial ao Projeto Político-pedagógico da escola pública brasileira. Cad. Cedes, Campinas, v.3, n. 61, p.283-301, dezembro, 2003.

SILVA, Janari R. N. Educação Ambiental No Contexto Do Projeto Político-Pedagógico De Duas Escolas Estaduais De Manaus-Am. IV Congresso de Pes. e Inov. da Rede Norte e Nordeste de Educação Tecnológica. Belém - PA. 2009.

Disponível em < http://connepi2009.ifpa.edu.br/connepi-anais/artigos/191_4075_1603.pdf >. Acesso em: 29 dez. 2013.

SMANEOTO et al. A Educação Ambiental Como Direito Fundamental Do Homem. Monografias Ambientais. vol.5, n5, p. $922-933,2012$.

SORRENTINO, M. Educação Ambiental e universidade: um estudo de caso. 1998. Tese (Doutorado). Faculdade de Educação da USP, São Paulo.

SOUZA, Maria G. G. Histórico da educação ambiental no Brasil. 2011. Monografia (Licenciatura em Ciências Biológicas)-Consórcio Setentrional de Educação a Distância, Universidade de Brasília, Universidade Estadual de Goiás, Brasília, 2011.

TRAJBER, R.; MENDONÇA, P. (Orgs.). Educação na diversidade: o que fazem as escolas que dizem que fazem educação ambiental. Brasília: Secretaria de Educação Continuada, Alfabetização e Diversidade, 2006. Disponível em; < http://unesdoc.unesco.org/images/0015/001545/154576por.pdf >. Acessado em 23 dez. 2013.

TBILISI- Conferência Intergovernamental de Tbilisi. Global Development Research Center. Disponível em; $<$ http.//www.gdrc.org/uem/ee/tbilisi.html>. Acessado em 23 jun. 2013.

TOMAZELLI, Maria G.C. FERREIRA, Tereza R.C. Educação Ambiental: Que Critérios Adotar Para Avaliar A Adequação Pedagógica De Seus Projetos? Ciência \& Educação, v.7, n.2, p.199-207, 2001.

TRAVASSOS, Edison Gomes. A educação nos currículos: dificuldades e desafios. Artigo 2001. Disponível em; $<$ http://eduep.uepb.edu.br/rbct/sumarios/p/educamb.pdf >. Acesso em 11 de ago. 2013.

VEIGA, A. Um retrato da presença da educação ambiental no ensino fundamental brasileiro: o percurso de um processo acelerado de expansão. Brasília: Instituto Nacional de Estudos e Pesquisas Educacionais Anísio Teixeira,

2003. 